\title{
Implementing Schoolwide Positive Behavior Support in High School Settings: Analysis of Eight High Schools
}

\author{
K. Brigid Flannery \\ University of Oregon \\ Jennifer L. Frank \\ Pennsylvania State University \\ Mimi McGrath Cato \\ University of Oregon \\ Bonnie Doren \\ University of Oregon \\ Pamela Fenning \\ Loyola University Chicago, pfennin@luc.edu
}

Follow this and additional works at: https://ecommons.luc.edu/education_facpubs

Part of the Education Commons

\section{Recommended Citation}

Flannery, BK, JL Frank, MM Cato, B Doren, and P Fenning. "Implementing Schoolwide Positive Behavior Support in High School Settings: Analysis of Eight High Schools." The High School Journal 96(4), 2013.

This Article is brought to you for free and open access by the Faculty Publications and Other Works by Department at Loyola eCommons. It has been accepted for inclusion in Education: School of Education Faculty Publications and Other Works by an authorized administrator of Loyola eCommons. For more information, please contact ecommons@luc.edu.

\section{(c) (1)(9)}

This work is licensed under a Creative Commons Attribution-Noncommercial-No Derivative Works 3.0 License. From High School Journal, Vol. 96(4), 267-282. Copyright @ 2013 by the University of North Carolina Press. Used by permission of the publisher. www.uncpress.unc.edu. 


\title{
Implementing Schoolwide Positive Behavior Support in High School Settings: Analysis of Eight High Schools
}

\author{
K. Brigid Flannery \\ University of Oregon \\ brigidf@uoregon.edu
}

Jennifer L. Frank

Pennsylvania State University

jlf51@psu.edu

Mimi McGrath Kato

University of Oregon

mmkato@uoregon.edu

Bonnie Doren

University of Oregon

bdoren@uoregon.edu

Pamela Fenning

Loyola University Chicago

pfennin@luc.edu

Schoolwide positive behavior support (SWPBS) is a systems-level intervention designed to prevent the occurrence of problem behavior and increase social competence. A growing body of research documents that SWPBS reduces problem behavior and improves academics (e.g., McIntosh, Chard, Boland, \& Horner, 2006), yet documentation of the feasibility of implementing SWPBS in high school settings is lacking. The current study examines implementation of universal SWPBS components in eight high schools serving over 15,525 students across a three-year period. Our findings were that improvements in implementation were evident between baseline and the end of year one, yet the implementation of SWPBS practices took a minimum of two years to achieve statistically significant and meaningful changes. These results suggest that unique aspects of the high school context may present specific implementation challenges.

Keywords: positive behavior support, high school, school-wide evaluation tool, discipline

The development of this article was supported in part by grants from the Institute of Education Sciences, U.S. Department of Education (\#R324A070157). Opinions expressed herein are the authors' and do not reflect necessarily the position of the U.S. Department of Education, and such endorsements should not be inferred.

(C) 2013 The University of North Carolina Press 


\section{Implementing Schoolwide Positive Behavior Support in High School Settings}

Schoolwide positive behavior support (SWPBS) is a systems-level approach based on the three-tiered model of prevention developed within public health. Walker and colleagues adapted it to fit educational settings (Walker et al., 1996; Walker \& Shinn, 2002). The goal is to establish the behavioral supports and social culture needed to improve the social and academic behavior of all students (Anderson \& Kincaid, 2005; Sugai, Horner, \& Lewis, 2009). Accordingly, the SWPBS model requires the implementation of evidenced-based practices and organizational systems that support the establishment of a social culture and individual supports needed to achieve social and academic success (Horner, Sugai, \& Anderson, 2010; Sugai et al., 2010). SWPBS is not a "packaged" program but rather provides a structured framework that a school team uses to guide the adoption of practices and design of a continuum of supports at three levels of intensity that match the context and needs of the school.

\section{Core Components of the Schoolwide Positive Behavior Support Framework}

This SWPBS framework requires schools to focus on optimizing several foundational systems and implement schoolwide practices designed to prevent and effectively respond to student misbehavior. Foundational systems within the SWPBS model include: (1) identification of important schoolwide outcomes for student learning and behavior; (2) development of organizational systems to support the implementation and sustainability of SWPBS practices; (3) implementation of evidence based practices to create a positive social climate and learning environment; and (4) use of data to monitor progress toward global schoolwide outcomes and facilitate effective data-based decisions (Sugai \& Horner, 2006).

These foundational systems are the necessary organizational building blocks needed by schools to successfully implement SWPBS. The foundational systems are interdependent and are intended to operate in unison so that schoolwide outcomes drive the adoption of systems to support the data-based implementation, evaluation, and modification of practices.

SWPBS leadership team. In order to implement these foundational systems, schools form a representative SWPBS leadership team responsible for overseeing and supporting the implementation of a multi-tiered array of evidence-based practices and the implementation of student data collection and progress monitoring. Specifically, the SWPBS school leadership team is charged with overseeing the collection and analysis of data to document changes and identify problems, establishing a continuum of evidence-based student supports, and maintaining staff and student commitment through ongoing communication (Metzler, Biglan, Rusby, \& Sprague, 2001; Schneider, Walker, \& Sprague, 2000; Sugai \& Horner, 2002; Warren et al., 2003).

Continuum of interventions and supports. The functional systems are used to support a continuum of evidence-based intervention and support that are organized according to a three-tiered prevention model (Walker et al., 1996; Walker \& Shinn, 2002). According to this model, universal (schoolwide) interventions are: (a) designed for all students and staff, (b) in place across all school environments, and (c) expected to successfully support about $80 \%$ of the students. At the universal level, the collection of data for decision-making focuses on the collection of universal academic and social behavior data and the use of these student data for systematic progress monitoring (Fairbanks, Sugai, Guardino, \& Lathrop, 2007; Fuchs \& Fuchs, 1986; Shinn, Walker, \& Stoner, 2002). Core practices at the universal level 
include: (1) defining and teaching expectations; (2) acknowledging and reinforcing appropriate social and academic behavior; (3) adopting consistent and effective consequences for misbehavior (Mayer, 1995; Sprick, Sprick, \& Garrison, 1992); and (4) integrating behavioral and academic practices to improve learning (Algozzine \& Algozzine, 2009; McIntosh, Horner, Chard, Boland, \& Good, 2006). The combination of implementing these universal interventions and supports, combined with the foundational systems to sustain them, represent the core features of SWPBS that all students receive.

However, for many students these universal supports will be insufficient. Therefore, in addition to these, schools also adopt a continuum of targeted and intensive intervention options for students who require additional levels of support. Targeted interventions are designed for subgroups of students who are not responsive to universal interventions but who do not require the most intensive individualized support. Students in these subgroups (usually around 15\% of the student population) receive the universal interventions but also need to have additional targeted supports such as study skills groups, social skills groups, and dropout prevention programs (Crone, Horner, \& Hawken, 2004; Simonsen, Meyers, \& Briere, 2010; Weisz, Jensen, \& McLeod, 2005).

Similarly, in the third level of support, intensive interventions, students who are not responding to the other two levels of interventions and thus are in need of individually designed supports are provided intensive individualized supports. Examples of intensive individualized supports include individual behavior support plans and wrap-around services (Eber, Hyde, \& Suter, 2011; Newcomer \& Lewis, 2004; Scott \& Caron, 2005). Due to the substantial time required by these interventions, schools strive for full implementation of universal and targeted supports first so that less than $5 \%$ of the population need the intensive services.

\section{Evidence for Effectiveness of SWPBS in High School Settings}

A growing body of research, comprised of descriptive or quasi-experimental studies (Barrett, Bradshaw, \& Lewis-Palmer, 2008; Bohanon et al., 2006; Horner, Sugai, Todd, \& Lewis-Palmer, 2005; Morrissey, Bohanon, \& Fenning, 2010) and randomized control studies (Bradshaw, Koth, Thorton, \& Leaf, 2009; Horner et al., 2009) has demonstrated that, when implemented with fidelity, SWPBS is effective at reducing the overall occurrence of problem behavior. A number of studies have also documented the positive impact of implementation on academic skills (e.g., Algozzine, Wang, \& Violette, 2011; Barrett et al., 2008; Horner et al., 2009). Importantly, however, the vast majority of this empirical work has been conducted in elementary and middle schools.

Although the effectiveness of SWPBS in elementary settings is fairly well established through randomized control trials (Bradshaw et al., 2009; Horner et al., 2009), the evidence in high schools settings is far more limited. Most investigations at the secondary level have been of limited scope, focused on a narrow set of outcome measures, and rarely included experimental designs. For example, a number of studies have been conducted in single schools, such as one four-year longitudinal study in a single school, which found cumulative decreases in student detentions (Luiselli, Putnam, \& Sunderland, 2002). In one urban middle school, Warren et al. (2006) demonstrated a $20 \%$ decrease in office disciplinary referrals and a $50+\%$ decrease in short-term suspensions over two years. Lassen, Steele, \& Sailor, (2006) also documented decreases in discipline referrals and improving academic performance. A longitudinal investigation of a single middle school indicated decreases 
in student office referrals across a two-year period (Taylor-Green et al., 1997). Unfortunately, none of these studies were in high schools nor used a comparison school, so it is unclear if these findings are causally related to using the SWPBS model.

One study of six middle schools and four high schools reported marked decreases in office discipline referrals (ODRs) and suspensions. This work documented improvements in statewide high school reading and math assessments in schools achieving high SWPBS implementation fidelity (Muscott, Mann, \& LeBrun, 2008). Bohanon et al. (2006) evaluated SWPBS in a single urban high school in the Midwest. Based on a significant reduction in ODRs and a decrease in the proportion of students with problem behaviors over a three-year evaluation, the authors concluded that these preliminary data provided support that implementation of SWPBS is a promising approach that can be effective in high school settings but additional studies were required.

\section{Adapting SWPBS for High School Settings}

Recent estimates suggest that at least 19,054 schools are actively implementing SWPBS but only 2,403 (12.6\%) of these are high schools (Horner, 2013). Although the exact reasons for this slow adoption rate by high schools are not entirely clear, implementation strategies used in elementary schools fail to take into consideration the unique contextual features of high schools (Flannery, Sugai, \& Anderson, 2009; Putnam et al., 2009).

Over the course of a longitudinal development study described below, we systematically adapted the implementation of the core features of SWPBS to enhance the fit with a secondary context. The literature related to transition to high school or restructuring of high school has documented these contextual differences between the elementary, middle, and high school (Daniels, Bizar, \& Zemelman, 2001; Murphy, Beck, Crawford, Hodges, \& McGaughy, 2001; Newman et al 2000; Sugai, Flannery \& Bohannon, 2004). A review of this literature reveals that several contextual features of high schools, such as size, culture, and developmental age of the students, may have strong influences on the implementation of SWPBS foundational systems of outcomes, systems, practices and data, which, in turn, impact ability to implement the key universal SWPBS practices (Figure 1; Table 1).

Figure 1: Conceptual Framework for Implementation of SWPBS in High Schools

CONTEXTUAL INFLUENCES

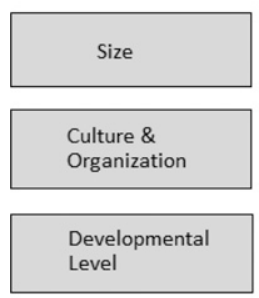

FOUNDATIONAL SYSTEMS
UNIVERSAL

PRACTICES

\section{OUTCOMES}

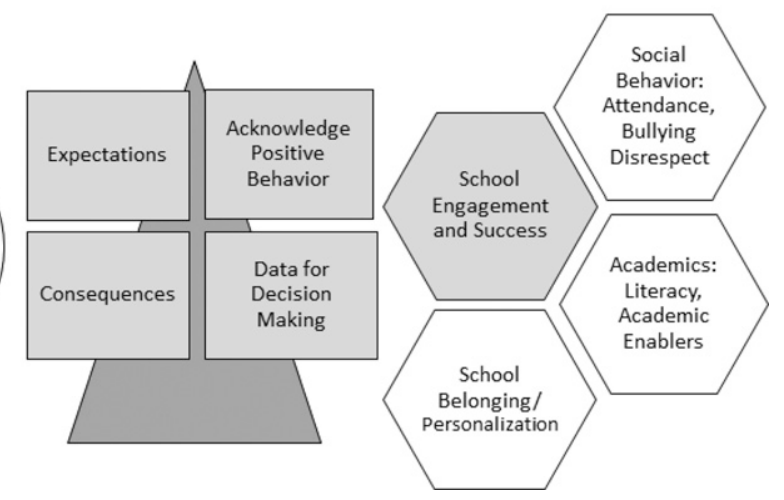


Table 1: Key Differences in SWPBS Implementation in High School

\begin{tabular}{|l|l|}
\hline Dimension & Key Aspects to Consider \\
\hline Size & $\begin{array}{l}\text { Larger classes; larger or multiple buildings } \\
\text { Diverse array of courses offered } \\
\text { Larger and more diversified staff } \\
\text { Teachers work with greater number of students } \\
\text { across day }\end{array}$ \\
\hline School Organization & $\begin{array}{l}\text { More complex administrative organization } \\
\text { Emphasis on departments vs. grade levels } \\
\text { Availability of professional services } \\
\text { (i.e., counseling) } \\
\text { Knowledge about school programs, etc. } \\
\text { decentralized and communication complex }\end{array}$ \\
\hline School Culture & $\begin{array}{l}\text { Responsible for focused content; not responsible } \\
\text { to promote social learning } \\
\text { Higher expectations for student self-management }\end{array}$ \\
\hline Student Developmental Level & $\begin{array}{l}\text { Students more autonomous } \\
\text { Stronger peer group influence } \\
\text { Greater need for student buy-in }\end{array}$ \\
\hline Outcomes & $\begin{array}{l}\text { Higher stakes for students and staff (i.e., testing } \\
\text { Emped to completion) } \\
\text { Emphasis on unique performance outcomes for } \\
\text { high schools more public }\end{array}$ \\
\hline
\end{tabular}

School size. In most cases, high schools tend to have a much larger and more diverse student population as compared to elementary school settings. In 2009-2010, the average enrollment of most public high schools in the U.S. was nearly twice that of elementary schools, and approximately $26 \%$ of all public high schools had exceptionally large enrollments of 1,000 or more students (Aud et al., 2012). As high schools are typically much larger than elementary schools, data collection and implementation of universal practices require a much higher level of effort and coordination. Similarly, in large school settings where teachers are responsible for multiple subjects per day with different groups of students, ensuring that students are exposed to a consistent set of expectations, consequences, and opportunities for positive acknowledgement and reinforcement can prove challenging.

School culture and organization. Several differences in the culture and organization of high schools can render SWPBS implementation much more difficult. First, unlike elementary schools, high school faculty are comprised of a much larger and more diverse array of teachers who are organized in departments or into small schools that often function rather independently and may have a fairly high degree of autonomy with regards to rule-making and pedagogical approaches. As a consequence of these departments and their training, it is not uncommon to find that high school teachers focus on teaching a specific content area, such as history or English, and lack interest in what is happening outside the classroom 
or teaching schoolwide expectations. Because of these more complex divisions within high schools, ensuring faculty buy-in and faculty-wide communication can be more difficult than is often the case in elementary settings. As such, when implementing SWPBS in high school settings, it is critical to ensure that leadership teams include representation of each major department or group within the school.

A second major contextual difference is that larger administrative teams with distinct roles and responsibilities typically lead high schools, which affects communication and decentralization of knowledge about what happens in the school. Whereas implementation of SWPBS in elementary school settings typically only requires buy-in and support from a single administrator, leadership representation in high school implementation scenarios may require obtaining support from several administrators who may have varying authority regarding the allocation of resources, curriculum management, and handling of student discipline.

Developmental level of students. At the student level, high school students differ fundamentally from younger students in ways that require adaptation of the SWPBS model. First, adolescents and young adults are more autonomous, place greater value on being actively involved in decision-making, and identify more closely with peer groups, often prioritizing peer interaction over academics. This difference suggests that stronger active involvement of students in the establishment of universal SWPBS practices (e.g., setting behavioral expectations, consequences, and systems to acknowledge positive behavior) is far more relevant and potentially beneficial for high school implementation. Second, the increased frequency of behavioral problems (Raffaele-Mendez, 2003), more violent types of misbehavior (Bohanon et al., 2006), and increased disengagement of adolescents from school (Crosnoe, 2001) render secondary school discipline issues distinct from those in elementary schools.

However, because high school students are more developmentally advanced, it is not uncommon to find that high school faculty are less likely to view teaching and reinforcing appropriate social behavior as their responsibility, as students are typically expected to have learned these skills and self-management prior to arriving in high school. Because of this, implementation of SWPBS in high school settings also often requires special consideration to ensure faculty buy-in regarding universal practices related to teaching expectations, ensuring consistent consequences, and acknowledging and reinforcing positive student behavior.

In summary, the research on the implementation of SWPBS in high schools is still in the early stages. There have been a few case study evaluations and some extant data analyses. In adopting an initiative such as SWPBS in the high school, one needs to consider the impact of high school contextual variables such as organization, developmental age of students, and school culture.

\section{Focus of the Current Study}

The purpose of the current study is to examine the feasibility and fidelity of SWPBS implementation across diverse high school settings. We hypothesized that while implementation of SWPBS in high school settings with some modifications would eventually be likely, full implementation of all SWPBS components within the typical one-year time frame may not be possible. Given the far greater size and organizational complexity of high schools, we anticipated that even with support, high schools would require an additional implementation year to fully implement the full complement of required SWPBS components. As this is the first study to 
longitudinally examine high school implementation patterns over time, we did not have any pre-existing hypotheses regarding the ease or difficulty of implementing specific SWPBS components.

\section{Method}

\section{Participants and Settings}

Participants in this study included eight diverse public high schools in two states in the Midwest and Pacific Northwest United States (Table 2). Three high schools were located in an urban locale, two were categorized as a suburban-to-urban location, and three were located in a small town non-adjacent to an urban center. The schools ranged in enrollment from 743 to 2,970 students with an average student enrollment of $1,940.63(S D=770.16)$. The average number of full-time classroom teachers was $107.38(S D=51.67)$. The average percentage of students receiving free or reduced-price lunch was $33 \%$, with the range being from $17 \%$ to $42 \%$. The percentage of minority students across all sites ranged from $11 \%$ to $54 \%(\bar{x}=28.97 \%)$. The average high school dropout rate was $2.36 \%$, ranging from of $5.7 \%$ to $0.7 \%$ across sites. At the beginning of the study, none of the schools participating had made Adequate Yearly Progress (AYP) based on their state AYP criteria in the previous school year. There were a total of seven school districts represented in this study (one district contained two high schools engaged in implementation). Districts comprising this sample served an average of 5.14 elementary schools, 1.8 middle schools, and 2.43 high schools. All participating schools were part of a larger U.S. Department of Education funded longitudinal study examining the effectiveness of the implementation of SWPBS model in high school settings. All participating schools were required to obtain district, administrator, and teacher assent in order to be included in the study.

Table 2: Participating High Schools

\begin{tabular}{|l|l|l|l|l|l|l|l|l|}
\hline School & \multicolumn{1}{|c|}{1} & \multicolumn{1}{c|}{2} & \multicolumn{1}{c|}{3} & \multicolumn{1}{c|}{4} & \multicolumn{1}{c|}{5} & \multicolumn{1}{c|}{6} & \multicolumn{1}{c|}{7} & \multicolumn{1}{c|}{8} \\
\hline Total Students & 1982 & 1149 & 775 & 1907 & 3041 & 2559 & 1976 & 2583 \\
\hline Total Teachers & 82.2 & 53.4 & 46.3 & 89.1 & 212 & 137 & 140 & 139 \\
\hline Percent Minority & 14.4 & 29.2 & 24.9 & 27.2 & 52.6 & 37.4 & 53.6 & 30.7 \\
\hline Percent FRL & 27.2 & 23.1 & 25.8 & 30. & 33.9 & 26.2 & na & 14.2 \\
\hline Dropout rate (\%) & 4.4 & 2.7 & 2.4 & 2.5 & 1.6 & .70 & 3.2 & 1.1 \\
\hline
\end{tabular}

\section{Intervention Components}

Formation of SWPBS school leadership team. The school leadership teams typically had between 10-15 members representing a wide variety of roles such as administrators, teachers, counselors, district staff, and truancy staff. Unlike at the elementary level, these teams can get quite large if focus is placed on representation across grade and content area as well as the related service personnel. Also the high school staff is more likely than the lower grade level staff to have extra duties such as choir, clubs, athletic coaching that makes their availability more difficult. The membership of each team was determined by the school with attention to such things as availability to participate throughout the year, leadership, and representation across the school. Although membership varied somewhat across sites, all teams were required to have the active participation of all relevant school administrators and representation of teachers across each major disciplinary area. They often developed a main team and then subcommittees to make the time availability and representation work. 
Development of action plan. Each leadership team was required to review the results of their performance on the primary SWPBS implementation measure, the Schoolwide Evaluation Tool (SET, described below), and then collaboratively develop an action plan to ensure that all foundational systems and universal practices would be implemented with integrity across school departments and grade levels. The team used the action plan to keep them focused and guide their work with the entire faculty and students.

Using data for decision-making. Each school was required to implement a comprehensive data collection system that would allow teams to monitor and analyze patterns in student disciplinary data. Although the specific software used varied, at a minimum the systems needed to use a common set of codes for describing student disciplinary infractions, locations where these infractions occurred, and a common set of codes for administrative responses/consequences. In addition, each data system was capable of outputting raw data so that teams could identify the most common types of student misbehaviors, most common locations where student misbehaviors occurred, typical administrative responses to student misbehavior, and data disaggregated by race, grade, gender, and Individual Education Program (IEP) status. The discipline data is similar to that at the lower grade-levels in that they examined office discipline referrals or climate surveys, but high schools also found the need to use additional data such as attendance data that was often collected and managed by other school personnel at the building or district level.

Professional development. Professional development was ongoing throughout the implementation process and occurred in several stages. The first stage consisted of training the school's SWPBS leadership team. These school teams received approximately 15-18 hours of intensive professional development in core SWPBS practices during the first year and 12 hours during the second year. The intensive leadership team training included the delivery of a series of modules that were developed using existing training material on the core components of SWPBS. The seven modules included: Impact of High School Context on Features of SWPBS; Strategies to Support Buy-in; Development of Infrastructure: Leadership Team, Communication, Decision Making; Using Data for Decision Making; Developing and Teaching Expectations; Developing Acknowledgement Systems; and Consequence Systems. The content was specifically oriented to put these components in place within the high school context by providing specific high school examples, strategies to remove potential barriers, and exploration of contextual issues.

Once leadership team members completed the intensive training, each team was required to develop briefer versions of this training for their faculty based on this intensive core training. Although the content and delivery varied slightly across sites, each school's faculty training included an overview of the SWPBS model, foundational systems the school would be implementing, and the nature of the universal practices that would be implemented (e.g., universal expectations, consequences, acknowledgement, and data collection practices).

In addition to being responsible for orienting their respective faculty to the SWPBS model, leadership teams were provided support to interpret their SET results and construct action plans to help them develop a specific plan for implementing and sustaining SWPBS practices. All teams conducted a thorough review of current practices related to student expectations and consequences for inappropriate behavior. Teams also examined school-level disciplinary data and patterns in the most common types of disciplinary problems and administrative consequences. After analyzing these 
practices, the school leadership team defined each common type of problem behavior and expectations for how teachers should respond (warning, teacher consequence, or office referral and disciplinary action). Further revisions were made to the content that would be shared with teachers at their faculty meetings, with a focus on attending to function, being consistent, and acknowledging appropriate behaviors. Subsequently, this information was provided to students in a large assembly or similar format.

Ongoing technical assistance. To help support the implementation of the SWPBS components, each participating school also received ongoing technical assistance based on their action plan, which varied across the buildings. The technical assistance staff met with each team approximately once per month and provided both logistical support and problem-solving to address the items on their action plans. The amount of technical assistance to the facilitator and team ranged from 20 to 65.5 hours $(\bar{x}=33.84 ; S D=16.46)$. The assistance was provided by project staff through a variety of mechanisms including team meeting attendance, phone-call or email contact to the internal high school team facilitator/coach, attendance at schoolwide events, and the provision of examples from other schools or resources.

Student involvement. Students were involved in the implementation of SWPBS processes in various ways. Across all sites, students were taught the expectations and received acknowledgements for demonstrating appropriate behaviors. Students also assisted in the development through the design of lesson plans to teach the expectations, delivery of the lesson plans, development of videos to teach the expectations or introduce SWPBS to the school, and design of assemblies focused on teaching expectations.

\section{Implementation Measures}

Schoolwide Evaluation Tool (SET). The SET (Sugai, Lewis-Palmer, Todd, \& Horner, 2001) is a multi-component assessment designed to measure implementation of SWPBS at the primary level. Project staff was trained to criterion on the administration and scoring of the SET by staff at the National Technical Assistance Center on Positive Behavior Interventions and Supports. The trained staff then conducted the SET at each project site. The administration includes interviewing administrators, teachers, and students, and evaluating permanent products (e.g., the school's referral form, school improvement plan, and discipline procedures). The SET consists of 28 items (scored on a three-point scale with $0=$ not implemented, $1=$ partial implementation, and 2 = full implementation) divided into seven subscales measuring whether schools have the essential features of SWPBS: (a) defined behavioral expectations, (b) taught behavioral expectations, (c) established on-going system for rewarding behavioral expectations, (d) a system for responding to behavioral violations, (e) engagement in ongoing behavioral monitoring and decision-making, (f) maintenance of effective management practices, and (g) securement of districtlevel support for ongoing implementation. Each implementation rating is criterionreferenced with regard to the specific practice in question. For a more in-depth description of the SET, please see Horner, Todd, Lewis-Palmer, Irvin, Sugai, and Boland (2004).

The SET has been found to have good reliability and validity and is useful for assessing the extent to which schools are implementing SWPBS (Horner et al., 2004; Vincent, Spaulding, \& Tobin, 2010). To address unique implementation variables identified by a national panel of experts in the implementation of SWPBS in high schools, four items were added to the SET related to students' involvement in and awareness of SWPBS and students' perception of the degree to which acknowledgement systems and staff's systematic delivery of praise was in place. 
The SET, inclusive of these additional items, will be referred to as the High School Schoolwide Evaluation Tool (HS-SET). These items included:

(a) Do staff members indicate they have systematically acknowledged (not including informal verbal praise) students in other ways that are different from the schoolwide reward system over the past two months?

(b) Does the administrator report that there is a mechanism for getting student input for PBS and that the input is representative of the student body?

(c) Do $50 \%$ or more of students asked indicate that they think students have provided input into the PBS program (i.e., survey, in team meetings, etc.)?

(d) Do $50 \%$ or more of students asked indicate that there is an adult in the school that knows them and they would go to if they needed help?

Two independent coders for each school completed the HS-SET during the summer prior to receiving the initial intervention training and at the end of the first and second years of implementation. Consistent with SET administration guidelines, at least 10 randomly selected staff and 15 randomly selected students (stratified across grade-level to ensure equal representation) were interviewed (Todd et al., 2012). Each observational period lasted approximately three hours. Inter-rater agreement was performed on over $65 \%$ of the HS-SET administrations and the reliability scores exceeded $80 \%$.

In the administration of the SET, students were randomly selected from multiple locations in the building and asked questions to determine (a) if they know the schoolwide expectations and their meaning in the different locations in the school, (b) if they received an acknowledgement for engaging in an appropriate behavior, and (c) whether they have an adult in the school who knows them, cares about them, and to whom they would go to if they needed help or had a problem.

\section{Results}

Means and standard deviations for each of the implementation scales are presented in Table 3. At the start of the study, the schools scored high on the District Support component with a mean across schools of 1.5 (out of 2 total possible), with five of the eight schools having all items in place. The schools initially scored low on practice components such as Expectations Defined, Expectations Taught as well as System for Rewarding Behavioral Expectations. After examining the descriptive results, we examined whether there was significant and meaningful change on implementation subscales from pre-intervention to end of year one and end of year one to end of year two. Paired $t$-tests of pre- to end-of-year changes (see Table 4) were performed. The significance levels within each time-point were adjusted for multiple comparisons

Table 3: Means and Standard Deviations of HS-SET Implementation Scores

\begin{tabular}{|l|c|c|c|c|c|c|}
\hline \multirow{2}{*}{} & \multicolumn{2}{|c|}{ Baseline } & \multicolumn{2}{c|}{ End of Year 1 } & \multicolumn{2}{c|}{ End of Year 2 } \\
\cline { 2 - 7 } & $M$ & $S D$ & $M$ & $S D$ & $M$ & $S D$ \\
\hline Expectations Defined & 0.69 & 0.80 & 1.06 & 0.78 & 1.31 & 0.75 \\
\hline Expectations Taught & 0.35 & 0.41 & 1.08 & 0.70 & 0.98 & 0.69 \\
\hline Rewards & 0.63 & 0.38 & 1.10 & 0.49 & 1.18 & 0.46 \\
\hline Response to Violations & 1.28 & 0.21 & 1.53 & 0.39 & 1.84 & 0.19 \\
\hline Monitoring & 1.25 & 0.52 & 1.31 & 0.46 & 1.75 & 0.30 \\
\hline Management & 1.03 & 0.71 & 1.53 & 0.29 & 1.54 & 0.34 \\
\hline District Support & 1.50 & 0.76 & 1.00 & 0.76 & 1.63 & 0.52 \\
\hline
\end{tabular}

Note. Each subscale mean could be from 0-2. 
Table 4: Changes in HS-SET Scores

\begin{tabular}{|l|l|l|l|l|l|l|l|l|l|}
\hline Scale & Timeframe & Mean $\Delta$ & Std & Lower & Upper & $t$ & $p$ & adj p & $d$ \\
\hline $\begin{array}{l}\text { Expectations } \\
\text { Defined }\end{array}$ & Y Year & 0.38 & 0.88 & -0.36 & 1.11 & 1.21 & 0.27 & 0.31 & 0.43 \\
\hline & 2 Years & 0.63 & 0.95 & -0.17 & 1.42 & 1.85 & 0.11 & 0.15 & 0.65 \\
\hline $\begin{array}{l}\text { Expectations } \\
\text { Taught }\end{array}$ & 1 Year & 0.73 & 0.43 & 0.37 & 1.08 & 4.80 & 0.01 & 0.07 & 1.70 \\
\hline & 2 Years & 0.63 & 0.53 & 0.18 & 1.07 & 3.35 & 0.01 & 0.03 & 1.18 \\
\hline Rewards & 1 Year & 0.48 & 0.48 & 0.08 & 0.87 & 2.81 & 0.03 & 0.09 & 1.00 \\
\hline & 2 Years & 0.55 & 0.45 & 0.17 & 0.93 & 3.45 & 0.01 & 0.04 & 1.22 \\
\hline $\begin{array}{l}\text { Response to } \\
\text { Violations }\end{array}$ & 1 Year & 0.25 & 0.44 & -0.12 & 0.62 & 1.60 & 0.15 & 0.22 & 0.56 \\
\hline & 2 Years & 0.56 & 0.35 & 0.27 & 0.85 & 4.58 & 0.00 & 0.02 & 1.62 \\
\hline Monitoring & 1 Year & 0.06 & 0.56 & -0.41 & 0.53 & 0.31 & 0.76 & 0.76 & 0.11 \\
\hline & 2 Years & 0.50 & 0.60 & 0.00 & 1.00 & 2.37 & 0.05 & 0.09 & 0.84 \\
\hline Management & 1 Year & 0.50 & 0.67 & -0.06 & 1.06 & 2.13 & 0.07 & 0.17 & 0.75 \\
\hline & 2 Years & 0.51 & 0.80 & -0.15 & 1.18 & 1.82 & 0.11 & 0.13 & 0.64 \\
\hline $\begin{array}{l}\text { District } \\
\text { Support }\end{array}$ & 1 Year & -0.50 & 0.76 & -1.13 & 0.13 & -1.87 & 0.10 & 0.18 & -0.66 \\
\hline & 2 Years & 0.13 & 1.13 & -0.82 & 1.07 & 0.31 & 0.76 & 0.76 & 0.11 \\
\hline
\end{tabular}

using a Benjamini-Hochberg correction. We selected paired $t$-tests as SWPBS implementation at the high school level is a relatively new area of research, and we were interested in exploring the significance and magnitude of change across years for each paired contrast at the outset of the study. Although Teaching Expectations $t(7)=4.80$, adj $p=0.07$ and Establishing a System for Rewarding Behavior $t(7)=2.81$, adj $p=.09$ approached significance by the end of year one, no significant changes in implementation were observed once $p$-values were corrected for multiple comparisons. Although not statistically significant, applying Cohen's (1988) guidelines of small $(d=0.20-0.49)$, medium $(d=0.50-0.80)$ and large $(d>0.80)$ effect sizes, the effect sizes for year one in Teaching Expectations $(d=1.70)$ and Establishing a System for Rewarding Behavior $(d=1.00)$ would be considered large. When examining changes across the first to second year of implementation, high schools attained statistically significant and meaningful improvements in the following components of the intervention model: Teaching Expectations $t(7)=3.35$, adj $p<0.05, d=1.18$, Establishing a System for Rewarding Behavior $t(7)=3.45$, adj $p<.05, d=1.22$, and Responding to Behavioral Violations $t(7)=4.58$, adj $p<.01, d=1.62$. Although meaningful improvement in Monitoring and Decision Making was evident by the end of year two $(d=0.84)$, adjusted $p$-values were not significant $t(7)=2.37$, adj $p=0.09, d=0.84$. Across the two years of implementation, there were no significant changes in Effective Management Practices $t(7)=1.82$, adj $p=0.13$ or District Level Support $t(7)=1.07$, adj $p=0.76$.

\section{Discussion}

The purpose of this study was to examine the pattern of change in the components of SWPBS across eight high schools. The findings demonstrated that, with support, high school teams could make changes in the implementation level of the SWPBS components; however, it required two years to gain significant change. During the first year, meaningful but non-significant changes emerged in the components of Teaching of Expectations and System for Rewarding Expectations. By the end of 
the second year, the mean changes in both of these subcomponents, as well as a System for Responding to Violations, were significant. A meaningful change was also noted for Monitoring Data and Decision Making, although this change was not significant. These changes indicate the important and overarching finding that high schools have the ability to implement SWPBS components with fidelity. Looking further, the study also demonstrated that implementation takes longer in high schools and that there are key areas on which high schools must focus when beginning implementation.

\section{Change Takes Longer in High Schools}

This study documented the condition, often anecdotally stated in high schools, that it takes longer to implement SWPBS in secondary schools relative to other settings. In elementary and middle schools, the SWPBS components are typically implemented more quickly, often within the first year (Bradshaw et al., 2009; Horner et al., 2009). The more complex structure of the high school (more people, more departments, and larger campuses) and the typical absence of involvement of all students and faculty in the implementation of the initiative can make this process slower. In fact, in one participating state, high schools referred to their first year of implementation as a 'zero year' because, during much of this first year, they were developing strategies to work together and obtain schoolwide buy-in to SWPBS. It was not until the second year that the high schools were in a position to more fully implement SWPBS practices. The high school staff reported that the addition of a 'zero year', one focused on planning and establishing foundational components (e.g., system-wide communication and buy-in, team structure, organization of data) to the levels of implementation aligned their progress better when compared with the elementary and middle schools in their districts.

\section{Establish Systems: Communication and Consensus}

Implementing SWPBS requires strong communication, consensus building, and schoolwide collaboration of all staff, students, and administrative team members. In most high schools, initiatives are often implemented at a department- or grade-level rather than on a system-wide (schoolwide) basis. Building schoolwide agreement takes more time and energy as stakeholders need to communicate about concerns and possible solutions and achieve consensus before implementing the initiative. Due to the size and lack of experience with schoolwide decision making, implementation of SWPBS in these high schools required tailored technical assistance to develop systematic strategies to achieve consensus from the broad range of stakeholders, including teachers, staff, and students. Additionally, due to the longer day and extra duties (clubs, athletics), it was often a challenge to find times when staff was available to meet as a group. The HS-SET documents the completion of necessary components, but it unfortunately does not measure what appear to be developmental processes in high schools such as communication or consensus-building that take time and planning to put in place prior to the development and implementation of SWPBS practices. Much of the work by the team in implementing SWPBS requires the establishment of a strong communication system and strategies for developing consensus among staff and students. As mentioned earlier, high schools often establish agreements on practices within their departments, but less often as a whole school.

Establish practice: expectations, acknowledgements, violation system. One component of SWPBS implementation is for schoolwide expectations (e.g., respect, perseverance, honor) to be defined, agreed upon and taught directly to the full school community. After the expectations are taught, the students are acknowledged when they demonstrate these expectations. As important is the alignment of the violation system with the expectations so that the consequences for noncompliance are consistently delivered. 
During the first two years, these high school implementation teams worked with their school staff and students to develop acceptable schoolwide expectations and strategies to teach them. Defining expectations required building consensus among staff as to the critical expectations that would be applicable in all settings, which took more time than what one would expect at elementary and middle school levels. High schools may already have some defined expectations for students, but due to the decentralized structure of high schools (e.g., different expectations based on department or individual teacher expectations) these expectations were not schoolwide and were often stated in the negative (e.g., no cell phones) or what students should not do rather than the positive behaviors in which they should engage.

Strategies for teaching often involved students as well as staff. For example, high schools often used strategies such as multimedia presentations or videos and older students as the instructors or "models" in an attempt to make the lessons more ageappropriate. The use of these strategies was growing in popularity, but can often take more 'up front' time (i.e., filming and editing a video or teaching a student group how to deliver a lesson plan) than the more traditional approach to teacher-led lesson plans. Because these efforts involved more students, however, the overall staff time required to prepare and implement them was reduced.

High schools typically have discipline systems already in place to address violations. These are the mechanisms through which behavioral infractions and their associated consequences are conveyed to the school staff and students. These systems are often complex, focus on negative sanctions for lack of compliance with written codes of conduct (Fenning et al., 2008; Fenning, Parragga, \& Wilczynski, 2000; Fenning et al., in press; Guest, 2011; Suarez, 1992), and are perceived by students as contributing to more school problems and a "culture of meanness" (MacDonald, 1997). To develop a more preventive code of conduct aligned with SWPBS requires a different way of thinking and responding (i.e., considering the function of the behavior), collaboration with key stakeholders, and considerations of curriculum issues (Fenning et al., in press; Fenning, Theodos, Benner, \& Bohanon-Edmonson, 2004). At the start of this study, the schools had traditional systems in place and these systems took time to change. But after determining their expectations, these schools spent time during the second year refining codes of conduct and consequence systems to better align with the newly defined expectations. This process required them to build consensus among faculty about what the appropriate behavior was, when a violation was dealt with in the classroom and when it was sent to the office. It also required the staff to agree on the use of a consequence system that was not one-size-fits-all but one that considers the function of the behavior (McIntosh, Kauffman, Carter, Dickey, \& Horner, 2009).

District level support. The schools in our sample had required district-level support (dedicated school liaison and available funding) to be in place at the beginning of the study. Most of these schools were part of a district that had been implementing SWPBS at the elementary and middle school level so, in some cases, they had put in place most of the district components. The lack of significant change in the District Level Support component across the study is not surprising due to the initial level being fairly high and that some level of district support was required for participation. The item that fluctuated across time was funding directed to SWPBS efforts.

\section{Limitations and Future Directions for Research}

Although the results of this study provide some initial information regarding potential implementation patterns of SWPBS in high school settings, some limitations are 
noteworthy. Because schools were not randomly selected, we cannot rule out the possibility that pre-existing characteristics among schools that agreed to participate biased the results. Moreover, our sample size was relatively small, and findings, although many were significant, were underpowered. As such, future research may wish to examine whether the results of this study generalize to a much larger, more diverse selection of schools (e.g., rural or high-poverty schools), or those serving special populations outside of the scope of the current study (e.g., alternative education schools, schools in juvenile justice settings, etc.). Second, although the SET is the most commonly used assessment of SWPBS implementation, it is not without its limitations. Although attempts are made to identify and assess a representative sample of faculty and students, not all eligible respondents are necessarily included in the survey. Moreover, although the SET has been validated in multiple studies (Horner et al., 2004), most have focused on data derived from elementary settings. Last, the schools in this study were supported by university faculty and received funds to cover costs of substitutes for the initial training and funds to cover additional data collection. These extra resources may not be available to other high schools beginning implementation.

The findings suggest that the evidence-based practice of SWPBS can be feasibly implemented systematically and with fidelity at the high school level. It also confirms the hypothesis from the case study of Bohanon et al. (2006) that those implementing SWPBS in high schools will see a slower process in getting the initial components in place. Research is needed to identify the specific barriers and strategies that increase implementation rates at the high school level.

SWPBS is a three-tiered model and this study focused only on the implementation of the universal, primary tier of prevention. Future research is needed on the feasibility of implementing all tiers of the model at the high school level and whether such implementation is associated with successful student outcomes for all students, such as reductions in problem behavior, increases in academic outcomes (e.g., GPA, grades), and improvement in retention and graduation rates. Similarly, a closer examination of which data collection options yield the highest level of utility for high school personnel would provide a better understanding of how SWPBS can be applied as a preventative approach in high schools. In doing so, these school communities can begin to enhance and better support students' behavioral and academic experiences.

\section{References}

Algozzine, B., \& Algozzine, K. (2009). Facilitating academic achievement through schoolwide positive behavior support. In W. Sailor, G. Dunlap, R. Horner, \& G. Sugai (Eds.), Handbook of positive behavior support (pp. 521-550). New York, NY: Springer Publishing Company. doi:10.1007/978-0-387-09632-2_22

Algozzine, B., Wang, C., \& Violette, A. S. (2011). Reexamining the relationship between academic achievement and social behavior. Journal of Positive Behavior Interventions, 13, 3-16. doi:10.1177/1098300709359084

Anderson, C. M., \& Kincaid, D. (2005). Applying behavior analysis to school violence and discipline problems: School-wide positive behavior support. The Behavior Analyst, 28, 49-63.

Aud, S., Hussar, W., Johnson, F., Kena, G., Roth, E., Manning, E., Wang, X., \& Zhang, J. (2012). The Condition of Education 2012 (NCES 2012-045). Washington, DC: U.S. Department of Education, National Center for Education Statistics. Retrieved from http://nces.ed.gov/pubsearch

Barrett, S., Bradshaw, C., \& Lewis-Palmer, T. (2008). Maryland statewide PBIS initiative: Systems, evaluation, and next steps. Journal of Positive Behavior Interventions, 10, 105-114. doi:10.1177/1098300707312541

Bohanon, H., Fenning, P., Carney, K., Minnis, M., Anderson-Harriss, S., Moroz, K., . . .Piggott, T. (2006). School-wide application of positive behavior support in an urban high school: A case study. Journal of Positive Behavior Interventions, 8, 131-145. doi:10.1177/10983007060080030201

Bradshaw, C., Koth, C., Thornton, L., \& Leaf, P. (2009). Altering school climate through school-wide positive behavioral interventions and supports: Findings from a group-randomized effectiveness trial. Prevention Science, 10, 100-115. doi:10.1007/s11121-008-0114-9

Cohen, J. (1988). Statistical power analysis for the behavior sciences. Hillsdale, NJ: Lawrence Erlbaum Associates, Inc. 
Crone, D., Horner, R. H., \& Hawken, L. S. (2004). Responding to problem behavior in schools: The behavior education program. New York, NY: Guilford Press.

Crosnoe, R. (2001). Academic orientation and parental involvement in education during high school. Sociology of Education, 74, 210-230.

Daniels, H., Bizar, M., \& Zemelman, S. (2001). Rethinking high school: Best practices in teaching learning and leadership. Portsmouth, VA: Heinemann, Reed Elsevier, Inc.

Eber, L., Hyde, K., \& Suter, J. (2011). Integrating wraparound into a schoolwide system of positive behavior supports. Journal of Child and Family Studies, 20, 782-790. doi:10.1007/s10826-010-9424-1

Fairbanks, S., Sugai, G., Guardino, D., \& Lathrop, M. (2007). Response to intervention: Examining classroom behavior support in second grade. Exceptional Children, 73, 288-310.

Fenning, P., Golomb, S., Gordon, V., Kelly, M., Scheinfield, R., Morello, T., . . Banull, C. (2008). Written discipline policies used by administrators: Do we have sufficient tools of the trade? Journal of School Violence, 7, 123-146. doi:10.1300/J202V07no3_08

Fenning, P., Parraga, M., \& Wilczynski, J. (2000). A comparative analysis of existing secondary school discipline policies: Implications for improving practice and school safety. In K. McClafferty, C. A. Torres, \& T. R. Mitchell (Eds.), Challenges of urban education: Sociological perspectives for the next century (pp. 237-252). Albany, NY: State University of New York Press.

Fenning, P., Pulaski, S., Morello, M., Maroney, E., Gomez, M., Schmidtt, A., \& Dahlvig, K. (in press). Call to action: Designing school discipline systems along a continuum of support. Journal of School Violence, Special Series, 3.

Fenning, P., Theodos, J., Benner, C. \& Bohanon-Edmonson, H. (2004). Integrating proactive discipline practices into codes of conduct. Journal of School Violence, 3, 45-61. doi:10.1300/J202v03n01_05

Flannery, K. B., Sugai, G., \& Anderson, C. (2009). Schoolwide positive behavioral support in high schools: Early lessons learned. Journal of Positive Behavioral Support, 11, 177-185.

Fuchs, L. S., \& Fuchs, D. (1986). Linking assessment to instructional intervention: An overview. School Psychology Review, 15, 318-323.

Guest, E. M. (2011). The impact of positive behavioral interventions and supports in secondary school settings. (doctoral dissertation). Retrieved from Scholarsbank.

Horner, R., (2013). Implementing evidence-based practices at scale with fidelity and impact. Institute for Education Science Project Director's Meeting, March 6, 2013, Washington D.C.

Horner, R., Sugai, G., \& Anderson C. M. (2010). Examining the evidence base for school-wide positive behavior support. Focus on Exceptionality, 42, 1-14.

Horner, R., Sugai, G., Smolkowski, K., Eber, L., Nakasato, J., Todd, A., \& Esperanza, J., (2009). A randomized, wait-list controlled effectiveness trial assessing school-wide positive behavior support in elementary schools. Journal of Positive Behavior Interventions, 11, 133-145. doi:10.1177/1098300709332067

Horner, R. H., Sugai, G., Todd, A. W., \& Lewis-Palmer, T. (2005). School-wide positive behavior support. In L. Bambara \& L. Kern (Eds.), Individualized supports for students with problem behaviors: Designing positive behavior plans (pp. 359-390). New York, NY: Guilford Press.

Horner, R. H., Todd, A. L., Lewis-Palmer, T., Irvin, L. K., Sugai, G., \& Boland, J. B. (2004). The School-Wide Evaluation Tool (SET): A research instrument for assessing school-wide positive behavior support. Journal of Positive Behavior Interventions, 6, 3-12. doi:10.1177/10983007040060010201

Lassen, S., Steele, M., \& Sailor, W. (2006). The relationship of school-wide positive behavior support to academic achievement in an urban middle school. Psychology in Schools, 43, 701-712.

Luiselli, J., Putnam, R., \& Sunderland, M. (2002). Longitudinal evaluation of behavior support interventions in public middle schools. Journal of Positive Behavior Interventions, 4, 182-188.

MacDonald, I. (June, 1997). School violence: Redirecting the storm chasers. Paper presented at the Annual Meeting of the Canadian Association for the Study of Educational Administration, St. Johns, Newfoundland, Canada.

Mayer, G. R. (1995). Preventing anti-social behavior in the schools. Journal of Applied Behavior Analysis, 28, 467-478.

McIntosh, K., Chard, D., Boland, J., \& Horner, R. H. (2006). Demonstration of combined efforts in school-wide academic and behavioral systems and incidence of reading and behavior challenges in early elementary grades. Journal of Positive Behavior Interventions, 8, 146-154. doi:10.1177/10983007060080030301

McIntosh, K., Horner, R. H., Chard, D., Boland, J., \& Good, R. (2006). The use of reading and behavior screening measures to predict non-response to school-wide positive behavior support: A longitudinal analysis. School Psychology Review, 35, 275-291.

McIntosh, K., Kauffman, A. L., Carter, D., Dickey, C. R., \& Horner, R. H. (2009). Differential effects of a direct behavior rating intervention based on function of problem behavior. Journal of Positive Behavior Interventions, 11, 82-93. doi: 10.1177/1098300708319127

Metzler, C. W., Biglan, A., Rusby, J. C., \& Sprague, J. R. (2001). Evaluation of a comprehensive behavior management program to improve school-wide positive behavior support. Education and Treatment of Children, 24, 448-479. doi: 10.1177/1098300708316258

Morrissey, K. L., Bohanon, H., \& Fenning, P. (2010). Teaching and acknowledging expected behaviors in an urban high school. Teaching Exceptional Children, 42, 27-35.

Murphy, J., Beck, L., Crawford, M., Hodges, A., \& McGaughy, C. (2001). The productive high school: Creating personalized academic communities. Thousand Oaks, CA: Corwin Press.

Muscott, H., Mann, E., \& LeBrun, M. (2008). Positive behavioral interventions and supports in New Hampshire: Effects of large-scale implementation of schoolwide positive behavior support on student discipline and academic achievement. Journal of Positive Behavior Interventions, 10, 190-205. 
Newcomer, L. L., \& Lewis, T. J. (2004). Functional behavioral assessment: An investigation of assessment reliability and effectiveness of function-based interventions. Journal of Emotional and Behavioral Disorders, 12, 168-181. doi: 10.1177/10634266040120030401

Newman, B. M., Lohman, B. J., Newman, P. R., Myers, M. C., \& Smith, V. L. (2000). Experiences of urban youth navigating the transition to ninth grade. Youth and Society, 31, 387-416.

Putnam, R., Romano, S., Agorastou, M., Baker, E., Irvin, L., O’Connell, D., Screiner, S., \& Stone, L. (2009). Establishing and maintaining staff participation in PBIS high schools. In B. Flannery \& G. Sugai (Eds.), SWPBS implementation in high schools: Current practice and future directions (pp. 43-56). Eugene, OR: University of Oregon. Retrieved from www.pbis.org

Raffaele-Mendez, L. M. (2003). Predictors of suspension and negative outcomes: A longitudinal investigation. New Directions for Youth Development, 99, 17-33.

Schneider, T., Walker, H., \& Sprague, J. (2000). Safe school design: A handbook for educational leaders. ERIC Clearinghouse on Educational management. Eugene, OR: University of Oregon.

Scott, T. M., \& Caron, D. B. (2005). Conceptualizing functional behavior assessment as prevention practice within positive behavior support systems. Preventing School Failure, 50, 13-20. doi:10.3200/PSFL.50.1.13-20

Shinn, M. R., Walker, H. M., \& Stoner, G. (Eds.) (2002). Interventions for academic and behavior problems II: Preventive and remedial approaches. Silver Spring, MD: National Association of School Psychologists.

Simonsen, B., Myers, D., \& Briere III, D. E. (2010). Comparing a behavioral check-in/check-out (CICO) intervention to standard practice in an urban middle school setting using an experimental group design. Journal of Positive Behavior Interventions (online first). doi:10.1177/1098300709359026

Sprick, R., Sprick, M., \& Garrison, M. (1992). Foundations: Developing positive school-wide discipline policies. Longmont, CO: Sopris West.

Suarez, T. M. (1992). Creating safe environments for learning in North Carolina's Public Schools. North Carolina Educational Policy Research Center.

Sugai, G., Flannery, K. B., \& Bohanon, H. (2004). School-wide positive behavior support in high schools: What will it take? Available at http://safeschools.dsisd.net/Elem5/HO3-1-24-08.pdf

Sugai, G., \& Horner, R. H. (2002). The evolution of discipline practices: School-wide positive behavior supports. Child and Family Behavior Therapy, 24, 23-50. doi:10.1300/J019v24n01_03

Sugai, G., \& Horner, R. H. (2006). A promising approach for expanding and sustaining schoolwide positive behavior support. School Psychology Review, 35, 245-259.

Sugai, G., Horner, R. H., Algozzine, R., Barrett, S., Lewis, T., Anderson, C., . . . Simonsen, B. (2010). Schoolwide positive behavior support: Implementers' blueprint and self-assessment. Eugene, OR: University of Oregon.

Sugai, G., Horner, R. H., \& Lewis, T. (2009). School-wide positive behavior support implementers' blueprint and self-assessment. Eugene, OR: University of Oregon, OSEP TA-Center on Positive Behavioral Interventions and Supports.

Sugai, G., Lewis-Palmer, T., Todd, A. W., \& Horner, R. H. (2001). School-wide evaluation tool set (SET). Eugene, OR: University of Oregon, Educational and Community Supports. Available at http://pbis.org/ tools.htm.

Taylor-Greene, S., Brown, D., Nelson, L., Longton, J., Gassman, T., Cohen, J. . . Hall, S. (1997). School-wide behavioral support: Starting the year off right. Journal of Behavioral Education, 7, 99-112.

Todd, A. W., Lewis-Palmer, T., Horner, R. H., Sugai, G., Sampson, N. K., \& Phillips, D. (2012). School-wide Evaluation Tool (SET) Implementation Manual (v2). Eugene, OR: University of Oregon, Educational and Community Supports. Available at http://www.pbis.org

Vincent, C., Spaulding, S., \& Tobin, T. (2010). A reexamination of the psychometric properties of the school-wide evaluation tool (SET). Journal of Positive Behavior Interventions, 12, 161-179. doi:10.1177/1098300709332345

Walker, H. M., Horner, R. H., Sugai, G., Bullis, M., Sprague, J., Bricker, D., \& Kaufman, M. H. (1996). Integrated approaches to preventing antisocial behavior patterns among school-age children and youth. Journal of Emotional and Behavioral Disorders, 4, 194-209. doi:10.1177/106342669600400401

Walker, H. M., \& Shinn, M. R. (2002). Structuring school-based interventions to achieve integrated primary, secondary, and tertiary prevention goals for safe and effective schools. In M. R. Shinn, H. M. Walker, \& G. Stoner (Eds.), Interventions for academic and behavior problems II: Preventive and remedial approaches (pp. 1-26). Bethesda, MD: National Association of School Psychologists.

Warren, J. S., Bohanon-Edmonson, H. M., Turnbull, A. P., Sailor, W., Wickham, D., Griggs, P., \& Beech, S. E. (2006). School-wide positive behavior support: Addressing behavior problems that impeded student learning. Educational Psychology Review, 18, 187-198.

Warren, J. S., Edmonson, H. M., Griggs, P., Lassen, S., McCart, A., Turnbull, A., \& Sailor, W. (2003). Urban applications of school-wide positive behavior support: Critical issues and lessons learned. Journal of Positive Behavior Interventions, 5, 80-91. doi:10.1177/10983007030050020301

Weisz, J. R., Jensen, A. L., \& McLeod, B. D. (2005). Development and dissemination of child and adolescent psychotherapies: Milestones, methods, and a new deployment-focused model. In E. D. Hibbs \& P. S. Jensen (Eds.), Psychosocial treatments for child and adolescent disorders: Empirically based approaches ( $2^{\text {nd }}$ ed., pp. 9-39). Washington, DC: American Psychological Association.

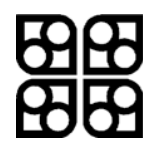

